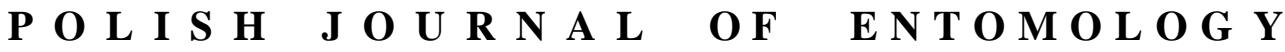

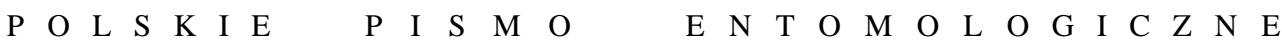

VOL. 84: $271-274$

Lublin

30 December 2015

DOI: $10.1515 /$ pjen-2015-0023

\section{Peritropis waclawi, a new species of Cylapinae from Namibia (Hemiptera: Heteroptera: Miridae)*}

\author{
JACEK GORCZYCA \\ Department of Zoology, University of Slilesia, Bankowa 9, 40-007 Katowice, Poland, \\ e-mail: jacek.gorczyca@us.edu.pl
}

\begin{abstract}
Peritropis waclawi a new species of Cylapinae is described on the basis of a single specimen collected in Namibia. The dorsal habitus of the new species is illustrated.
\end{abstract}

KEY WORDS: Heteroptera, Miridae, Cylapinae, new species, Namibia.

\section{INTRODUCTION}

The subfamily Cylapinae is a relatively small group of mirids inhabiting warm regions of the world. Most its representatives are probably fungivorous, although some of them are also carnivorous (GoRCZYCA 2000, 2006, PluOT-SigWALT \& CHÉROT 2013). The genus Peritropis UHLER, 1891 is one of the most numerous in species within the subfamily occurring mostly in tropical and subtropical regions of the world. Most species of the genus inhabit the Afrotropical Region, from where almost 30 species have been described (GORCZYCA 2006), and in South America where 21 species are known (WOLSKI \& HENRY 2012).

Among material collected in Namibia I found a specimen of the subfamily Cylapinae which is a new species of the genus Peritropis. Its description is provided below.

\footnotetext{
* The paper is dedicated to Prof. Wacław WOJCIECHOWSKI in recognition of his great contribution to the taxonomy and faunistics of Hemiptera.
} 


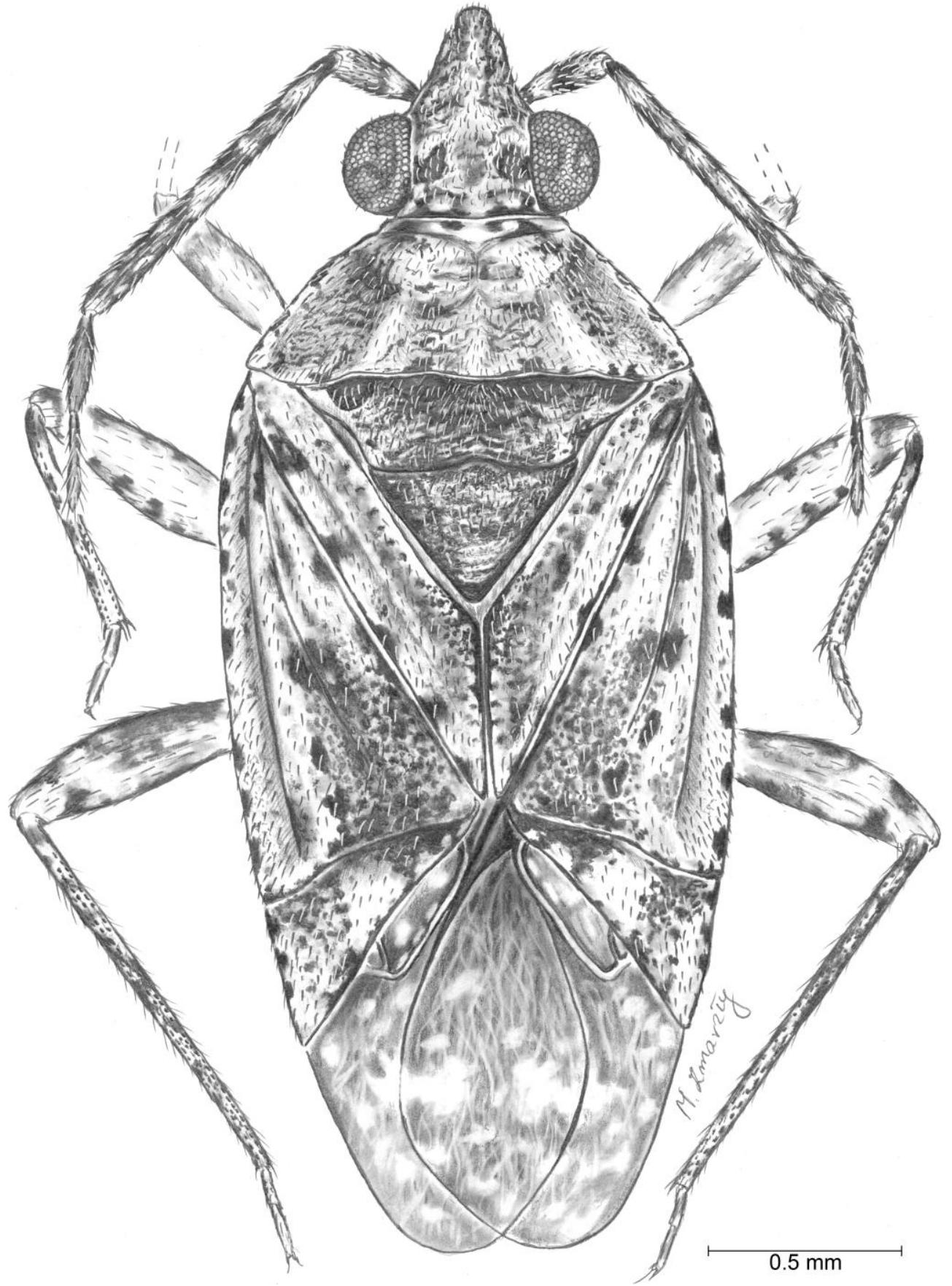

Fig. 1. Peritropis waclawi sp. nov. holotype, dorsal habitus. 


\section{TAXONOMY}

\section{Peritropis waclawi sp. $\mathbf{n}$.}

\section{Etymology}

I dedicate this species to Wacław WoJCIECHOWSKI, the well-known Polish aphidologist and also my friend on the occasion of his $70^{\text {th }}$ birthday.

\section{Type material}

Holotype (male): Namibia, Onguma Lodge, 05. 12. 2014, 1055 m, at light, Etosha NP., leg. R. Doвosz. Housed in the Upper Silesian Museum, Bytom, Poland.

\section{Diagnosis}

The new species is rather similar to Peritropis vanharteni LINNAVUORI \& GORCZYCA, 2002 but differs in its bigger size ( $P$. vanharteni $-2.55-2.60 \mathrm{~mm}$ ), shorter second antennal segment $(P$. venharteni $-1.0 \mathrm{~mm})$, and the colouration of the body and membrane with paler spots and patches (Fig. 1).

\section{Description (male)}

Body pale with dark brown patches and spots. Body length $3.22 \mathrm{~mm}$, width $1.24 \mathrm{~mm}$. Head white mottled with small brown patches, covered with short, white, shiny, scale-like setae, vertex with distinct occipital carina and two larger brown patches contiguous with inner margins of eyes (Fig. 1), clypeus slightly tinged red. Length of head $0.53 \mathrm{~mm}$, width $0.64 \mathrm{mmm}$, diameter of eye $0.17 \mathrm{~mm}$. Antennae inserted in tubercles contiguous with margins of eyes. First antennal segment short, thick, brown, white at base and apex, covered with short pale setae. Second segment brown with pale patches, covered with pale and dark setae, thickened slightly towards apex. Third and fourth segments short, brown covered with pale protruding setae longer than their diameter, fourth segment divided. Length of antennal segments in mm: 0.31: 0.90: 0.23: 0.29. Labium thin, brown reaching abdomen, length of individual segments not measurable in the specimen examined. Pronotum pale with numerous brown and a few red and orange patches, lateral margins distinctly elevated with a few dark spots on sides, anterior lobe of pronotum raised, posterior margin sinuate. Length of pronotum $0.43 \mathrm{~mm}$, anterior margin of pronotum 0.41 $\mathrm{mm}$, lateral margins $0.54 \mathrm{~mm}$, posterior margin $1.13 \mathrm{~mm}$. Mesoscutum relatively large, raised, mesoscutum and scutellum brown mottled with numerous small, pale patches, covered with pale, short, scale-like setae.

Hemelytra pale with numerous small brown patches and with two large brown patches contiguous with costal fracture, covered with short, dark brown and white setae, embolium slightly tinged orange, with small dark brown patches in margins, clavus pale mottled with 
brown patches, cuneus relatively wide, with pale and brown patches, slightly tinged orange. Membrane pale grey with a paler pattern (Fig. 1).

Body ventrally dark brown with pale and red patches, coxae and trochanters white, femora pale with dark brown and red patches, tibiae pale with dark brown pattern, tarsi very short, pale brown, claws with a subapical tooth.

\section{ACKNOWLEDGEMENTS}

I would like to thank Roland DoBosz (Department of Natural History, Upper Silesian Museum, Bytom, Poland) who collected the Miridae specimens in Namibia, Marzena ZMARZŁY (Department of. Zoology, University of Silesia, Katowice, Poland) for drawing of the dorsal habitus of the new species and the two anonymous reviewers for providing valuable comments.

\section{REFERENCES}

GoRCZYCA J. 2000. A systematic study on Cylapinae with a revision of Afrotropical Region (Heteroptera, Miridae). Prace Naukowe Uniwersytetu Śląskiego, Katowice $\mathrm{N}^{\circ} 1863$. Wydawnictwo Uniwersytetu Ślą̧siego, Katowice.

GorCZYCA J. 2006. The Catalogue of the subfamily Cylapinae KIRKALDY, 1903 of the World (Hemiptera, Heteroptera, Miridae). Monographs of the Upper Silesian Museum 5. Upper Silesian Museum, Bytom.

LinNAVUORI R., GORCZYCA J. 2002. Two new species of Peritropis Uhler from the Arabian Peninsula (Heteroptera: Miridae: Cylapinae). Genus 13(2): 183-188.

Pluot-Sigwalt D., ChÉRot F. 2013. Donnés biologiques et anatomiques, régime alimentaire et taxonomie d'un nouveau Fulvius afrotropical (Insecta, Heteroptera, Miridae, Cylapinae, Fulviini). Zoosystema 35(1): 45-68.

Wolski A., Henry T. 2012. Revision of the New World Species of Peritropis Uhler (Heteroptera: Miridae: Cylapinae). Insect Systematic and Evolution 43(3-4): 213-270.

Received: 16 July 2015

Accepted: 27 August 2015 